\title{
ODYNOPHAGIA: A RARE PRESENTING SYMPTOM IN ACUTE MYELOID LEUKEMIA (FAB AML - M2)
}

Sudip Yadav ${ }^{1 *}$, Neeta Kafle ${ }^{2}$, Sulav Sapkota ${ }^{3}$

\begin{abstract}
Affiliation
1. Medical Officer, Department Of Emergency, Birat Medical College and Teaching Hospital.

2. Lecturer, Department of Pathology, Birat Medical College and Teaching Hospital.

3. Assistant Professor, Department of Internal Medicine, Birat Medical College and Teaching Hospital.
\end{abstract}

\section{ARTICLE INFO}

Received : 16 December, 2020
Accepted : 17 March, 2021
Published : 15 June, 2021

(c) Authors retain copyright and grant the journal right of first publication with the work simultaneously licensed under Creative Commons Attribution License CC - BY 4.0 that allows others to share the work with an acknowledgment of the work's authorship and initial publication in this journal.

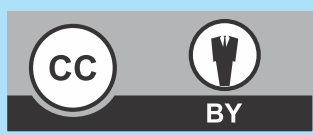

CR 39

DOI: https://doi.org/10.3126/bjhs.v6i1.37665

\section{* Corresponding Author}

Dr. Sudip Yadav

Medical Officer

Department of Emergency

Birat Medical College Teaching Hospital

Email: sudipyadav013@gmail.com

ORCID ID: http://orcid.org/0000-0002-4625-8440

\section{Citation}

Sudip Yadav, Neeta Kafle, Sulav Sapkota. Odynophagia: A Rare Presenting Symptom In Acute Myeloid Leukemia (FAB AML - M2) BJHS 2021;6(1)14.1419-1421.

\section{ABSTRACT}

Acute myeloid leukemia is more common in adults than in children population. Fatigue, bleeding and fever are the most common presentations. Petechiae, gingival swelling, lymphadenopathy and hepatosplenomegaly are common signs. Here we report a case of a 57 years post-menopausal lady with gum swelling and pain on deglutition for both liquid and solid foods. She was diagnosed with a case of AML- M2 on the basis of peripheral blood smear and bone marrow examination findings.

\section{KEYWORDS}

Acute myeloid leukemia, blast cells, bone marrow examination, deglutition, fatigue 


\section{INTRODUCTION}

Acute myeloid leukemia ( $A M L)$ is a neoplasm characterized by arrest in the maturation of myeloid cell lineages and proliferation of immature cells (blast cells) that ultimately fills the blood compartment resulting in bone marrow failure. It accounts for $80 \%$ of cases in the adult population with average age at the time of diagnosis being 65 years. ${ }^{1}$ Most of the patient present with fever, bleeding from natural orifices, anaemia related symptoms like easy fatigability and shortness of breath, lymphadenopathy, hepatosplenomegaly and musculoskeletal symptoms. ${ }^{2}$ To our knowledge so far, there are no such cases of AML who presented with odynophagia in the literature. Here we present a case of acute myeloid leukemia who presented with odynophagia as an initial presentation.

\section{CASE REPORT}

A 57 years post-menopausal lady presented at the Emergency of Birat Medical College and Teaching Hospital (BMCTH) with complaints of gum swelling and pain on swallowing for both solid and liquid for two weeks. The patient denied the history of gum bleeding or bleeding from other sites, fever, weight loss and headache. She denied having any comorbid conditions or use of any drugs.On general examination, she was pale and her vitals were stable. Systemic examination was within normal limit .On Investigation, she had anaemia (haemoglobin $7.0 \mathrm{gm} / \mathrm{dl}$ ),

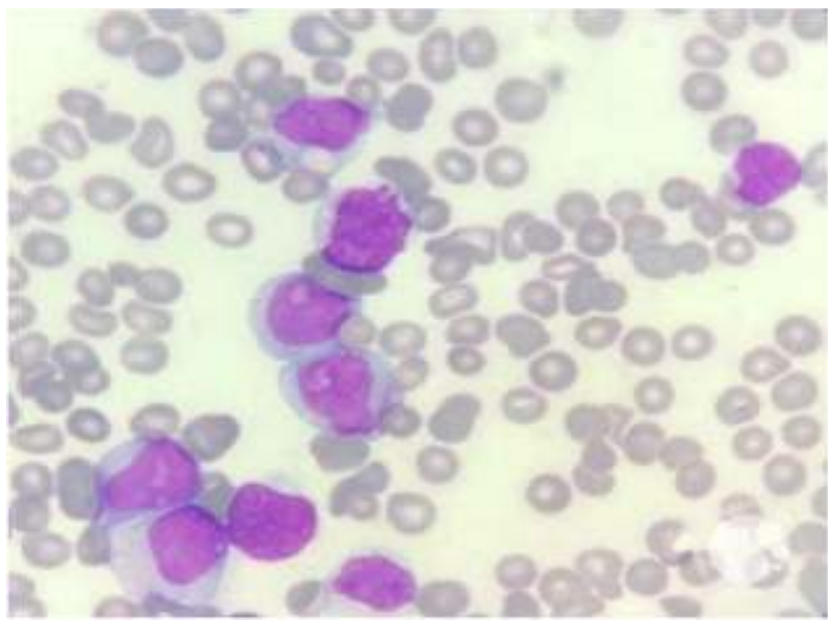

Figure 1: Peripheral smear of patient of acute myeloid leukemia showing myeloblasts, which are large cells with high nucleo-cytoplasmic ratio and nucleoli.( Stained with Wright-Giemsa Stain, Magnification 100X)

leukocytosis $(74,000 / \mathrm{cu} \mathrm{mm})$, thrombocytopenia $(36,000 / \mathrm{cu} \mathrm{mm})$. Her peripheral blood smear examination revealed significant number of blast cells $30 \%$ (figure 1 ) neutrophils $50 \%$, lymphocytes $17 \%$ and eosinophils $3 \%$. Bone marrow examination showed blast cells $40 \%$, promyelocyte $5 \%$,myelocyte $8 \%$, metamyelocyte $8 \%$, neutrophils $30 \%$,eosinophils $4 \%$ and monocyte $5 \%$.She was admitted and started with tablet Hydroxyurea 1 gram per oral thrice a day for 3 days along with six pints of fresh blood and four pints of fresh frozen plasma transfusion and other conservative treatment. She was planned to get induction therapy but she collapsed on third day of treatment.

\section{DISCUSSION}

AML is a haematological neoplastic condition arising from myeloid precursor cells characterized by disordered differentiation and proliferation of myeloid precursor cells ultimately infiltrating immature cells (blast cells) in bone marrow and blood compartment. Beside this, other body tissues like lymph node, spleen, gingiva, skin, eyes, oropharynx, central nervous system may be also involved. ${ }^{3}$ Common risk factors include ionizing radiation, use of cytotoxic drugs, genetic conditions and immunosuppressive states. ${ }^{4} \mathrm{AML}$ is further subdivided into eight types ( $\mathrm{MO}-\mathrm{M} 7$ ) according to French-American -British (FAB) Classification and four major categories according to $\mathrm{WHO}^{5}$

Acute Myeloid Leukemia has varying presentation as fever, fatigability and bleeding from orifices are the common presenting features. One observational study conducted from January 2011 to May 2012 by Faseeh Sahab and Fazli Raziq on 618 bone marrow biopsy report of acute leukemic patients showed : fever(77\%), pallor (33\%) and bleeding disorder(23\%) as the most common presenting complaint and other manifestations like generalized body ache (18\%), abdominal pain (15\%), lymph node enlargement (13\%), weakness(8\%) and weight loss(7\%) as presenting features. ${ }^{6}$ Oral manifestations are also common like paleness of mucosa, gingival hyperplasia, gum bleeding, ulcerative lesions, cracked lips and bullae over tongue. ${ }^{7}$

Odynophagia has multiple causative factors e.g. oropharyngeal causes (infections, tumour, foreign body, trauma), esophageal motility disorders and systemic causes (autoimmune condition, immunosuppressive states, drugs/toxins). Odynophagia is an uncommon presenting symptom in patients of leukemia. One literature shows that it is more common during the course of treatment after receiving chemotherapy rather than initial presentation in acute myeloid leukemia. ${ }^{8}$

Presence of blasts cells $20 \%$ or more in peripheral blood smear or bone marrow that manifests characteristic morphological, cytochemical, immunophenotypic, cytogenetic and molecular features is diagnostic. ${ }^{9}$ This condition can be treated with combination chemotherapy, supportive care, psychological and familial support. Allogenic hematopoietic stem cell transplantation has favourable survival outcome. ${ }^{10}$ 


\section{CONCLUSION}

This case emphasizes that medical expertise should be cautious regarding oral manifestations of systemic diseases and highlight odynophagia as one of the presenting symptom in AML. So, early evaluation of anaemic patient in elderly age group who present with odynophagia, acute myeloid leukemia should also be evaluated after ruling out the primary cause of odynophagia.

\section{CONFLICT OF INTEREST}

None

\section{REFERENCES}

1. Vakiti A, Mewawalla P. Acute Myeloid Leukemia. [Updated 2020 Nov 21]. In: StatPearls [Internet]. Treasure Island (FL): StatPearls Publishing; 2020 Jan

2. Lyengar V, Shimanovsky A. Leukemia. [Updated 2020 Aug 10]. In: StatPearls [Internet]. Treasure Island (FL): StatPearls Publishing; $2020 \mathrm{Jan}$

3. Gurbuxani S, A Schiffer C. Clinical manifestations, pathologic features, and diagnosis of acute myeloid leukemia [Internet]. uptodate. 2019 [cited 15 December 2020]. Available from: https://www.uptodate.com

4. Davidson S. The principle and practice of medicine. 22nd ed. Edinburgh: livingstone; 2014.

5. Silvana ANGELESCU A. Value of Multifaced Approach Diagnosis and Classification of Acute Leukemias [Internet]. PubMed Central (PMC). 2021 [cited 24 May 2021]. Available from: https://www. ncbi.nlm.nih.gov/pmc/articles/PMC3566891/

6. Shahab F, Raziq F. Clinical Presentations of Acute Leukemia. Journal of the College of Physicians and Surgeons Pakistan 2014;24:5.
7. Cammarata-Scalisi F, Girardi K, Strocchio L, Merli P, Bernardin A, Galeotti $A$ et al. Oral Manifestations and Complications in Childhood Acute Myeloid Leukemia. Cancers. 2020;12(6):1634.

8. Chung J, Richter S, Wazir A, Rahman H, Naseer U, Fitzpatrick M et al. 1731 Leukemic Infiltration Leading to Esophagitis: A Rare Initial Presentation of AML. American Journal of Gastroenterology. 201:

9. E Colitz J. Overview of acute myeloid leukemia in adults [Internet]. uptodate. 2020 [cited 15 December 2020]. Available from: https://www.uptodate.com

10. Jackson K, Kennedy G, Mollee P, Marlton P, Morris K. Intensive chemotherapy and reduced-intensity allogeneic hematopoietic stem cell transplantation for acute myeloid leukemia in elderly patients. Asia-Pacific Journal of Clinical Oncology. 2014;10(3):246254.9;114(1):S970-S971.FAB M2 